\title{
Design and Realization of Process Control System based on VB Configuration Software
}

\author{
Sun Bei ${ }^{1, a}$, Bai Yan ${ }^{2, b}$ \\ ${ }^{1}$ Beihua University Mechanical Engineering College \\ ${ }^{2}$ BeiHua University Engineering Training Center \\ abyw1689@sohu.com, ${ }^{b} 745575912 @ q q . c o m$
}

Keywords: VB, PID control,Configuration Software,Remote Monitoring and Control

\begin{abstract}
Taking VB as a developing platform, the thesis constructs a real-time,interactive and extending virtual laboratory system. This system can make full use of network resource,reduce hard ware investing,which makes it a low-cost,high profit information-based foundation with prodigious practical signification.
\end{abstract}

\section{Introduction}

Process control is a subject based on experiments, which has a vital status in automation education,even the whole scientific education.How to carry through the process control experimental education is always a key problem.From the developing point of control study itself which is full of scientific exploring activities,it is by all means the trend that we put research experiment in practice a broad in the process of education[1].

The system is made of three pars:the physical model that was developed in the Engineering Training Center of BeiHua University,the 87C196KC Single-Chip Microcomputers, and the personal Computer.The serial communication between lower-computer and master-computer is based on Modbus communication protocols with the RS-232 interface.The experiments are developed and organized by means of configuration software[2].In this system,more then twenty conventionality process control experiments are realized,which contained the Object-Properties Test,the Singe Loop Control system,the Cascade Control system,the Forward Control system,the Forward-Feedback Control system and so on.

\section{The overall design of the process control system}

Critical PC software, each link to the realization of the function of the organization and scheduling, experiment, test analysis, special consideration is necessary for system development and extension.On software design,we use simply and friendly man-machine interface,real-time simulating scene and collecting all the data, such as temperature,valve's caliber and all device's status.And in order to make operator know scene directly,we form text chart,pole chart and so on with these collected data.On the other side, the system has break bounds alarm,dynamic trouble detecting,shift management,operating records and report auto forming module[3].

\section{The hardware design process control experimental device}

The experimental device is composed of the controlled object, detection device, executing mechanism and interface module.The controlled object is composed of three tank water and boiler system.Detection device used in the platform includes a pressure sensor, a flow sensor and a temperature sensor and the liquid level sensor.The actuating mechanism comprises an electric control valve, and pump frequency converter[4].The input signal of the output signal of the sensor and actuator are analog values, and computer processing of digital signal, so the need to A/D and $\mathrm{D} / \mathrm{A}$ converter will convert digital signals and analog signals. $\mathrm{A} / \mathrm{D}$ and $\mathrm{D} / \mathrm{A}$ conversion module test system by using the ICP-7017/7033 module and ICP-7024 module of I7000 series intelligent data acquisition module Taiwan Hongge company in the production .The hardware system as shown in Fig2.Schematic diagram of process control experiment device as shown in Fig1. 


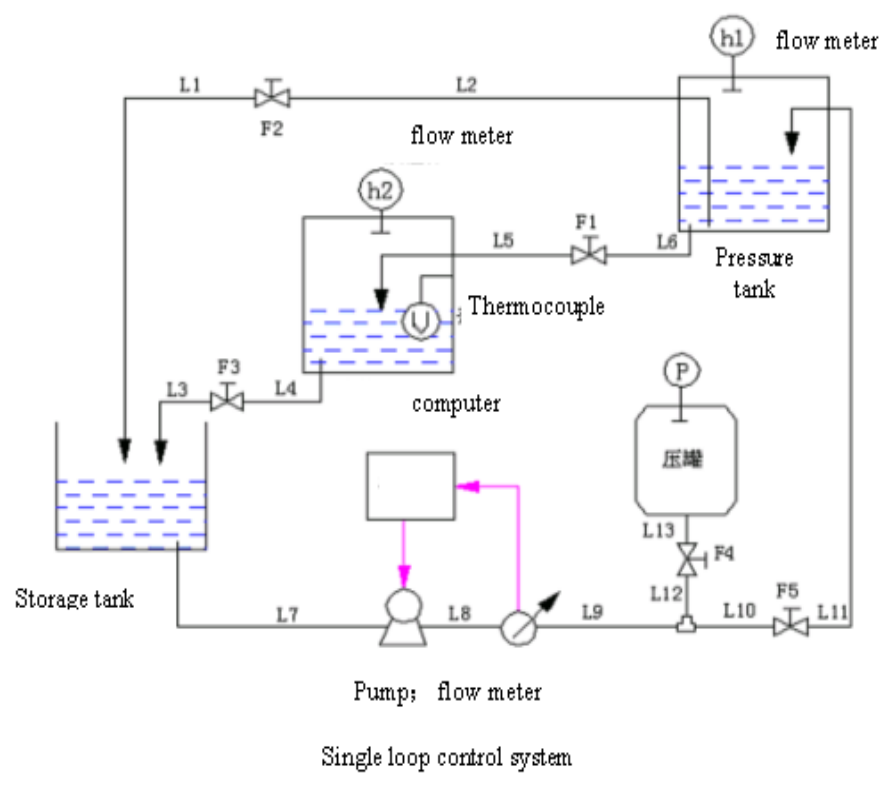

Figure1 Schematic diagram of process control experiment device

\section{The software design process control experimental device}

On software design,we use simply and friendly man-machine interface,real-time simulating scene and collecting all the data, such as temperature,valve's caliber and all device's status. And in order to make operator know scene directly,we form text chart,pole chart and so on with these collected data.On the other side, the system has break bounds alarm,dynamic trouble detecting,shift management,operating records and report auto forming module.The experiments are developed and organized by means of configuration software .In this system,more then twenty conventionality process control experiments are realized,which contained the Object-Properties Test,the Singe Loop Control system,the Cascade Control system,the Forward Control system,the Forward-Feedback Control system and so on.Configuration interface as shown in Fig3.

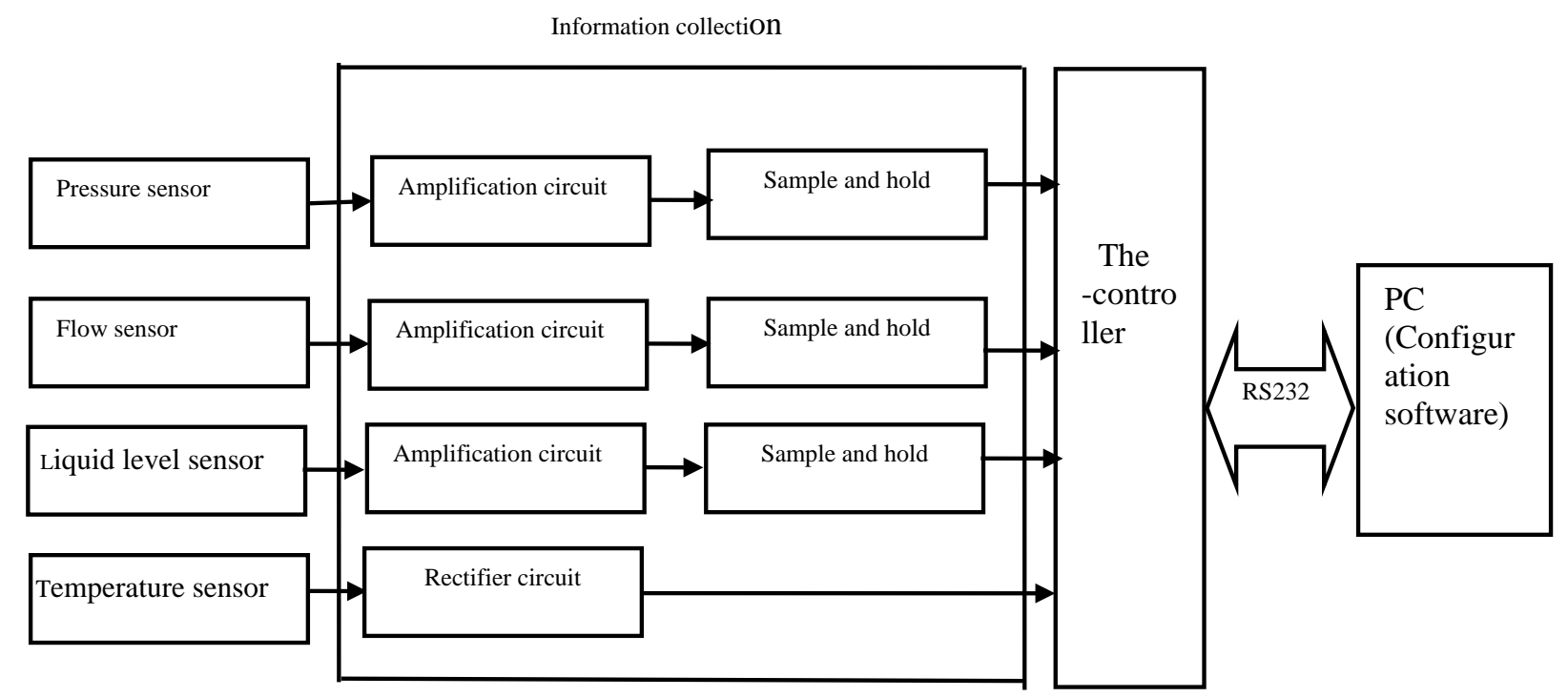

Figure 2 Hardware structure chart of process control experiment 


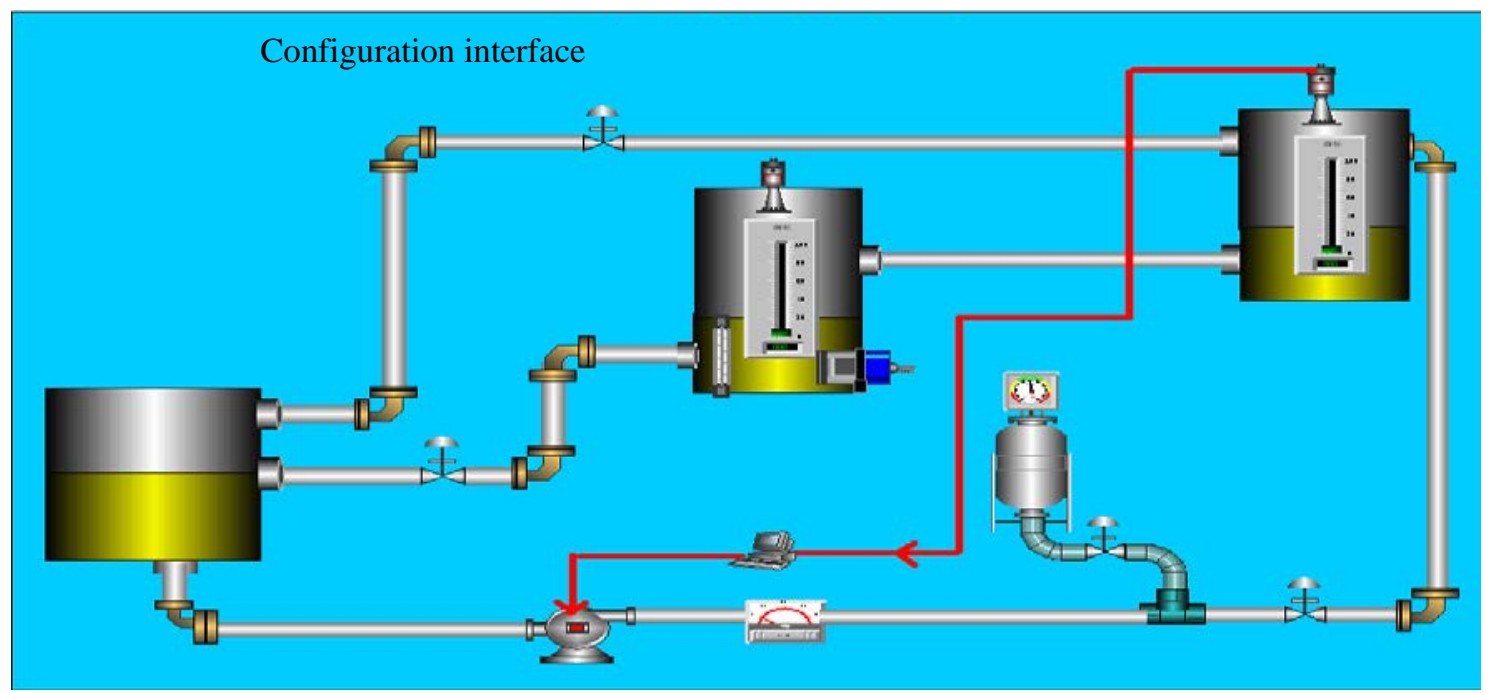

Figure 3 Configuration interface

\section{Effect of operation display}

Effect of operation display as shown in Fig4.

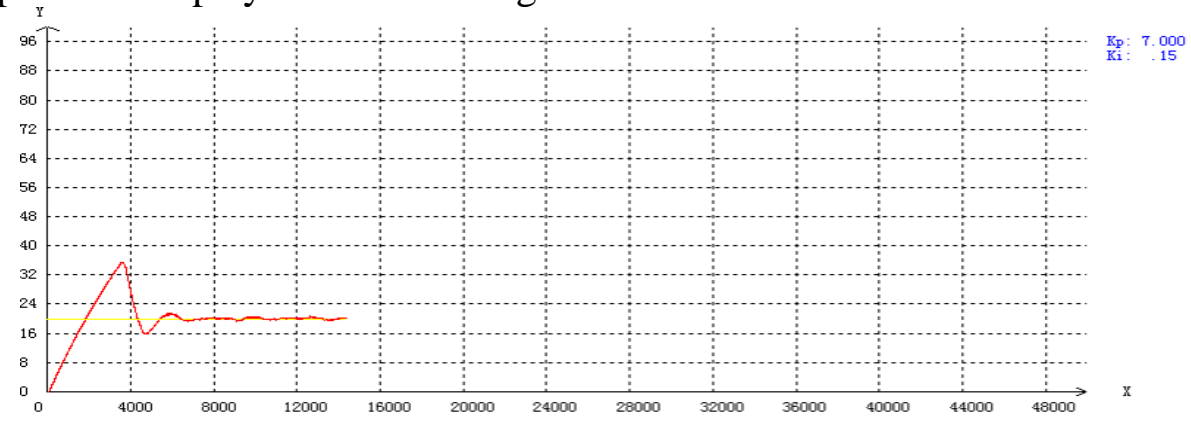

Figure 4 Effect of operation display

The experiment platform is open and has a good interface. It provides the simulation and the real-time control experiment environment for courses of "Automatic Control Theory" and "Process control system" and so on .At the same time it can be a suitable hardware in-the-loop experimental platform for advanced control theory 's research..

\section{PID control and its control algorithm AND Configuration interface design}

In the process of the industry production,a kind of complex controlling object with the characteristic of multi-variable and nonlinear can be found commonly.The seeking of the appropriate controlling strategies and the realization method of high effect can be seen as hot-spot in field of industrial controlling. The great requirements of mathematical calculation from such kind of complex controlling strategies with are applied in locale producing device can be fulfilled by combining configuration software with MATLAB.

As a typical case of process control, level control has the characteristics of large delay,nonlinear,time-varying.At present,the traditional PID control method are used in the actual liquid level control, however,it is difficult of adjust the appropriate PID parameters for delay system and also difficult to achieve the desired control effect.Fuzzy control dose not rely on the mathematical model of the controlled object,its adaptability and robustness are better,so it's suitable for nonlinear systems.According to the characteristics of two-tank water level control system, we used the fuzzy control approach and achieve the two-tank liquid level automatic control[5]. 


\section{PID control and its control algorithm}

$$
\begin{aligned}
& y(t)=K_{p}\left[e(t)+\frac{1}{T_{i}} \int e(t) d t+T_{d} \frac{d e(t)}{d t}\right] \\
& G(s)=\frac{U(s)}{E(s)}=K_{P}\left(1+\frac{1}{T_{i} s}+T_{d} s\right)
\end{aligned}
$$

According to the requirements ,A fuzzy controller for PID parameter adjustment with two input and three output.The controller uses $|e|$ And $|e c|$ As input,As the output to KP, KI, KD.Domain input language variables e and ec are $\{-0.8,-0.2,0,0.2,0.8\}$, The output linguistic variables KP, KI, KD by single closed-loop experimental parameters range stability.

According to the control specifications PID parameter adjustment principle above can get the

\begin{tabular}{|c|c|c|c|c|c|c|c|c|c|c|c|c|c|c|c|c|c|}
\hline \multicolumn{6}{|c|}{ The funzy control rule table KP } & \multicolumn{6}{|c|}{ The fiazy cortrol rule table $\mathrm{Ki}$} & \multirow{2}{*}{$\frac{\mathrm{NC} \mathrm{KP}}{\mathrm{NB}}$} & \multirow{2}{*}{$\begin{array}{c}\mathrm{NB} \\
\mathrm{S}\end{array}$} & \multirow{2}{*}{$\begin{array}{c}\mathrm{NM} \\
\mathrm{s}\end{array}$} & \multirow{2}{*}{$\begin{array}{l}z 0 \\
z\end{array}$} & \multirow{2}{*}{$\begin{array}{c}\text { PM } \\
S\end{array}$} & \multirow{2}{*}{$\begin{array}{c}\mathrm{PE} \\
\mathrm{S}\end{array}$} \\
\hline${ }^{e c} \mathrm{KP} e$ & NB & NM & zo & PM & $\mathrm{pB}$ & ${ }^{e c} \mathrm{KP} \mathrm{e}$ & NB & NMM & zo & PM & $\mathrm{PB}$ & & & & & & \\
\hline NB & $\mathbf{M}$ & B & B & B & $\mathbf{M}$ & NB & $z$ & $z$ & $z$ & $z$ & $z$ & \multirow{2}{*}{ NM } & \multirow{2}{*}{ M } & \multirow{2}{*}{$\mathrm{M}$} & \multirow{2}{*}{$\mathrm{s}$} & \multirow{2}{*}{$\mathrm{M}$} & \multirow{2}{*}{$\mathrm{M}$} \\
\hline NMM & $\mathrm{s}$ & $\mathrm{s}$ & $\mathrm{M}$ & $\mathrm{s}$ & $\mathrm{s}$ & NM & $\mathrm{s}$ & M & $M$ & $\mathrm{M}$ & $\mathrm{s}$ & & & & & & \\
\hline$z_{0}$ & $s$ & $\mathrm{M}$ & B & $\mathrm{M}$ & s & $z_{0}$ & $\mathrm{M}$ & B & $\mathrm{B}$ & ${ }_{B}$ & M & $z_{0}$ & $\mathrm{~s}$ & M & B & $\mathrm{M}$ & s \\
\hline PM & $\mathrm{s}$ & $\mathrm{s}$ & $M$ & $\mathrm{~s}$ & $s$ & PM & & $M$ & & $M$ & S & $\mathrm{PM}$ & $M$ & $\mathrm{M}$ & $\mathrm{s}$ & $\mathrm{M}$ & M \\
\hline PB & $\mathrm{M}$ & B & B & $\mathrm{B}$ & $\mathbf{M}$ & PB & $z$ & $z$ & $z$ & $z$ & $z$ & $\mathrm{pB}$ & $\mathrm{s}$ & s & $z$ & s & s \\
\hline
\end{tabular}
output variables KP, KI, KD as shown in Table 1.

Table 1 Fuzzy control rules table

\section{Part of the program of VB software}

\section{For $\mathrm{i}=1$ To $\mathrm{L}$}

$$
\mathrm{d}(\mathrm{i})=0
$$

Next i

For $\mathrm{i}=\mathrm{L}+1$ To $\mathrm{P}$

Next $\mathrm{i}$

$$
d(i)=d d(i-L)
$$

For $\mathrm{i}=1$ To $\mathrm{P}$

$$
\text { tmp }=\text { yout }
$$$$
\text { tmp }=(\text { alfa } \wedge \mathrm{i}) * \operatorname{tmp}+(1-(\text { alfa } \wedge \mathrm{i})) * r_{-} \text {val }
$$

Next i

$$
p p(i)=\operatorname{tmp}
$$

If counter $=0$ Then

For $\mathrm{i}=1$ To $\mathrm{P}$

$$
\text { tmp }=d(i) *(p p(i)-y(i))
$$

Next i

sum $=$ sum + tmp

deta_u $=$ sum

uout $=$ uout $+1 *$ deta_u

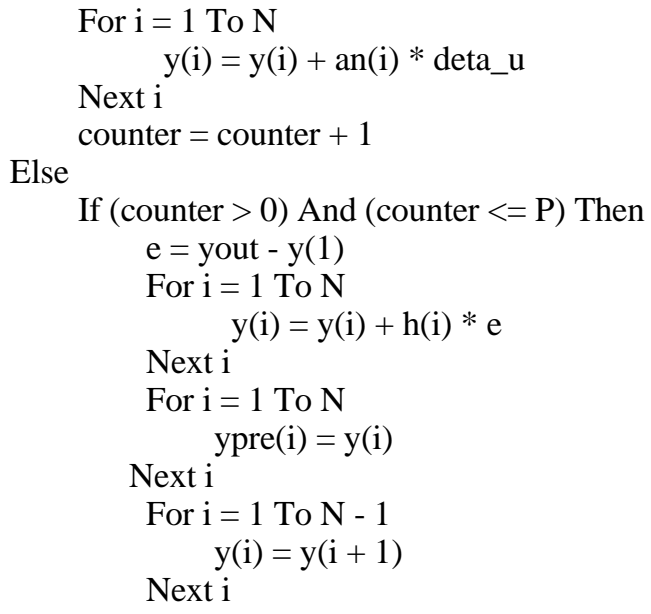

\section{Conclusion}

At present this system has been applied to the process control technology and system.It was used in real-time and remote monitor to control six process controlling experimental facilities such as, pressure,liquid-level,temperature/flux.A example of flux control is presented to be exploited remote step response identification experiment,remote PID control experiment, remote PID control experiment and custom arithmetic experiment.The results of the experiments demonstrate the characters of the system such as real-time,dynamic behavior and cross-platform,and provide the anticipated platform. 


\section{References}

[1].C Edwards.How VB software jacks-up Web app Professional,2005,(12/l):10 1

[2].GALLUZZO M,DUCATO R,BARTOLOZZI V,PICCIOTTO A.Expert control of DO in the aero-bi reactor of an activated sludge process. Computers\&Chemical Engineering . 2001

[3].M Batty.The AJAX project:New theory,and new software for space syntax[J].SPACE SYNTAX 5TX INTERNATIONAL SYMPOSIUM 2005,VOL 1,PROCEEDINGS.2005,(12/1):10 11

[4].Wan T J.An application of artificial neuromolecular system for effluent quality prediction of wastewater treatment plant. Chinese Instrument Environment Engineering . 2000

[5].Jiang Wei. System Identification Methods and Applications. National Defence Industry Press. 2010 